\title{
Políticas públicas para o livro, leitura e biblioteca
}

\author{
Flávia Goullart Mota Garcia Rosa \\ Mestra em ciência da informação pelo PPGCI/UFBA. Professora da \\ EBA/UFBA. \\ E-mail: flaviagoulartgr@yahoo.com.br
}

Nanci Oddone

Doutora em ciência da informação (UFRJ/Ibict). Professora do PPGCI/ UFBA.

E-mail: neoddone@uol.com.br

\section{Resumo}

O artigo passa em revista as políticas públicas nacionais para o livro, a leitura e as bibliotecas. Recupera seus antecedentes históricos, discute sua situação atual e analisa suas perspectivas. Descreve os programas governamentais mais recentes, apontando as contradições e desigualdades que os caracterizam.

\section{Palavras-chave}

Políticas públicas para o livro, leitura e biblioteca. Analfabetismo. Analfabetísmo funcional. Indicadores de analfabetísmo funcional. Cenário da leitura no Brasil. Lei Rouanet. Plano nacional do livro e leitura. Brasil.

\section{Public policies for book, reading and library}

\section{Abstract \\ The article analyses Brazilian national public policies for book publishing, reading and for libraries. It recoveries the history of those policies, discusses their present situation and evaluates their perspectives. Recent government programmes on this issue are described and have their contradictions and inequalities pointed.}

\section{Keywords}

Public policies for the book, reading and library. Reading and library. Illiteracy. Functional illateracy. Functional illetaracy indicators. Scenario of reading in Brazil. Rouanet Law. National book and reading plan. Brazil.

\section{UM BREVE PANORAMA DA LEITURA NO BRASIL, CENÁRIO CONTRADITÓRIO E DESIGUAL}

O Brasil tem a maior produção editorial da América Latina e é responsável por mais da metade dos livros editados no continente (LINDOSO, 2004). Com uma indústria editorial bem-sucedida, apesar de uma trajetória que se iniciou tardiamente no século XIX, chegou-se ao novo milênio vendo consolidada essa indústria, notadamente no que diz respeito à qualidade gráfico-editorial. Possui razoável número de editoras em atividade - 530 editoras concentradas nas regiões Sul e Sudeste, segundo a Câmara Brasileira do Livro (CBL), e 114 editoras universitárias, conforme dados da Associação Brasileiras de Editoras Universitárias (Abeu) - e um mercado potencial que tem despertado a cobiça dos grandes grupos editoriais estrangeiros, sobretudo por conta do mercado de livros didáticos altamente financiado pelo governo federal. Mesmo assim, existem fatores que interferem no seu processo de expansão. O baixo índice de leitura de sua população talvez seja o obstáculo mais comprometedor para a superação das dificuldades e é uma conseqüência das condições socioeconômicas e educacionais da população do país.

Ainda que a Constituição Federal, no seu Título I - Dos Princípios Fundamentais, disponha como objetivos fundamentais uma sociedade livre, justa, solidária, com a redução das desigualdades sociais e a erradicação da pobreza, e, no Capítulo II - Dos Direitos Sociais, assegure ao cidadão direitos sociais como educação, trabalho, lazer, saúde, segurança, moradia (BRASIL, 1988), o Índice de Desenvolvimento Humano (IDH) do Brasil traduz uma situação de desigualdade social e de não-cumprimento do que determina a Constituição.

O IDH é a síntese de três fatores - longevidade, educação e renda - apresentados no Relatório de Desenvolvimento Humano do Programa das Nações Unidas para o Desenvolvimento. Situa o Brasil em 63a posição entre 177 países auditados, ficando atrás, inclusive, de sete países da América Latina: Argentina (34으), Chile (37을,

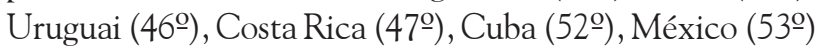
e Panamá (56ㅇ) (AFP, 2005). Além do IDH, outros índices são preocupantes não apenas pelo seu reflexo na atividade editorial especificamente, mas porque demonstram que o país ainda está distante de alcançar o desenvolvimento nacional e a cidadania. 
Com relação ao analfabetismo, uma pesquisa nacional denominada Indicador de Alfabetismo Funcional (Inaf), realizada pelo Instituto Paulo Montenegro - Ação Social do Ibope e pela ONG Ação Educativa, tem como dados conclusivos o seguinte:

\begin{tabular}{lccc}
\hline $\begin{array}{l}\text { Habilidade de } \\
\text { alfabetismo }\end{array}$ & Inaf 2001 & Inaf 2003 & Inaf 2005 \\
\hline Analfabetismo absoluto & $9 \%$ & $8 \%$ & $7 \%$ \\
Muito baixa & $31 \%$ & $30 \%$ & $31 \%$ \\
Básica & $34 \%$ & $37 \%$ & $38 \%$ \\
Plena & $26 \%$ & $25 \%$ & $26 \%$ \\
\hline
\end{tabular}

Fonte: Instituto Paulo Montenegro/Ibope

A pesquisa do Inaf, ao estabelecer "[...] correlação entre letramento e condição social, [tornou] possível perceber que, [...] quanto menor o tempo de escolaridade e a condição socioeconômica, tanto menor é o desempenho do candidato" (BRASIL, 2005). Conclui-se que a condição socioeconômica é fator responsável não só pela permanência do aluno na escola, mas também pelo seu desempenho para alcançar satisfatoriamente o letramento.

Dados do Instituto Nacional de Estudos e Pesquisas Educacionais Anísio Teixeira (Inep) reforçam os dados apresentados e revelam que existe atualmente no Brasil mais de 16 milhões de analfabetos. Considerando os analfabetos funcionais, caracterizados como pessoas com menos de quatro séries concluídas, são mais de 33 milhões de analfabetos. A região Nordeste concentra quase 50\% desse contingente, e, por esses indicadores, pode-se relacionar o baixo desenvolvimento econômico dessas regiões e conseqüentemente as desigualdades regionais do país. A Bahia está entre os cinco estados onde se situa metade dos analfabetos do país na distribuição total de analfabetos absolutos. E, apesar de ser, dentre eles, o estado que mais possui escolas, apresenta o menor percentual de escolas com bibliotecas: 7,06\%, como foi citado pelo jornal A Tarde (LIVRO, 2005).

Em que pesem os problemas de analfabetismo, o baixo índice de leitura e as discussões sobre o futuro do livro, este é ainda considerado "[...] o mais poderoso instrumento do saber jamais inventado pelos homens [...]" (CROPANI, 2004). Os autores da Lei no 10.753 , conhecida como a "Lei do Livro" de 30 de outubro de 2003 e que institui a Política Nacional do Livro, definiram o livro como "o meio principal e insubstituível (grifo nosso) da difusão da cultura e transmissão do conhecimento, do fomento à pesquisa social e científica, da conservação do patrimônio nacional, da transformação e aperfeiçoamento social e da melhoria da qualidade de vida" (BRASIL, 2003).

Convivendo com outros meios eletrônicos de armazenamento e acesso à informação, o conhecimento que circula na sociedade ainda tem no livro o seu principal meio e nas bibliotecas o local para a guarda do acervo e da memória de um povo. Segundo Eco, "as bibliotecas, ao longo dos séculos, têm sido o meio mais importante de conservar nosso saber coletivo. Foram e são ainda uma espécie de cérebro universal onde podemos reaver o que esquecemos e o que ainda não sabemos" (2003, p.2). Apesar de saber a "fórmula" para fazer circular a informação inclusive com as novas tecnologias que facilitam o acesso à informação, a questão da leitura não está firmada. Não basta ter acesso, é fundamental que, ao longo da sua formação escolar, o indivíduo seja estimulado à prática da leitura. Caso contrário, o livro não cumpre sua função, como questiona Chartier (1998, p. 154),

[...] um livro existe sem leitor? Ele pode existir como objeto, mas sem leitor, o texto do qual ele é portador é apenas virtual. Será que o mundo do texto existe quando não há ninguém para dele se apossar, para inscrevê-lo na memória ou transformá-lo em experiência?

Nesse sentido, acrescenta-se que, se o indivíduo não incorpora a prática de leitura, não desenvolve de forma satisfatória as habilidades necessárias ao uso do conhecimento para poder entender, compreender e apreender. De acordo com a American Library Association (1989),

[...] Para ser competente em informação, uma pessoa deve ter habilidade para reconhecer quando a informação é necessária e ter a capacidade para localizar, avaliar e suprir efetivamente a necessidade de informação. Para produzir tal cidadão será necessário que escolas e faculdades compreendam e integrem o conceito de information literacy (competência em informação) nos seus programas de aprendizagem e que elas desempenhem um papel de liderança na preparação dos indivíduos e instituições para tirar vantagem das oportunidades inerentes à sociedade da informação. Finalmente, pessoas com competência em informação são aquelas as quais aprenderam a aprender. [...].

Para Cropani (1998), citado por Barros (2005), baseado em estudos globais encomendados pela Unesco, os fatores críticos que fortalecem o estabelecimento das práticas de leitura de um povo ou mesmo de um indivíduo são os seguintes: ter nascido em uma família de leitores; ter 
passado a juventude em um sistema escolar preocupado com o estabelecimento da prática de leitura; o preço do livro e o valor simbólico que a população atribui ao livro. Dadas essas pré-condições, verifica-se que expressiva parcela da população não possui condições de desenvolver a prática leitora. Embora a escola seja um espaço adequado para o contato do leitor com essa prática, observa-se que o ambiente escolar não tem sido explorado adequadamente para atingir a meta de formar leitores. Essa questão é mais grave nas nações com altos índices de cidadãos não-alfabetizados, entre as quais se inclui o Brasil.

Quanto aos estudantes do 30 grau, a maioria ingressa na universidade sem habilidades leitoras amadurecidas. Isso fica mais acentuado na cultura de pré-vestibular, já que o ensino médio tem se voltado quase exclusivamente para facilitar o acesso à universidade. $\bigcirc$ material didático básico utilizado pelos estudantes nesse período é de conteúdo reducionista. Como exemplo, os módulos e resumos de textos de literatura e de demais disciplinas. Os próprios cursinhos e escolas reproduzem esses materiais didáticos, que são compilações de várias obras, raramente citadas ou referenciadas. Soma-se, a esse quadro, o fato de a relação do estudante com os livros estar sendo fragilizada pelo surgimento de novos suportes de informação propiciados pelo advento das tecnologias de informação e comunicação. A atual sociedade apóiase cada vez mais na cultura digital, o que também traz implicações para a indústria editorial. Segundo Freitas e Silva (1998, p. 87),

Por um lado, o professor universitário constata que a leitura decodificação [...] não é suficiente para que o aluno possa fazer, via texto, o nível de intermediação necessário na construção do seu conhecimento. Essa leitura é quase sempre classificada como "ingênua", "pobre". Por outro lado, os professores universitários, inclusive os de língua e literatura, se eximem da tarefa de lidar com o ensino da leitura, promovendo uma espécie de adiamento às avessas do problema, ou seja, procrastina-se a responsabilidade com a "empreitada" aos graus anteriores: responsabilidade com o ensino da leitura cabe $[. .$.$] aos professores de português do 1^{\circ}$ e $2^{\circ}$ graus. Assim, o ensino da leitura na escola assume o papel de verdadeira "batata quente": ninguém quer segurar o encargo e a questão é arremessada de mão em mão num sucessivo adiamento de responsabilidade.

Um fato a ser considerado é o baixo poder aquisitivo da população e o conseqüente obstáculo à aquisição de bens culturais, que contribui para que o livro seja tido como artigo de luxo. Pesquisa encomendada pelo Banco
Nacional de Desenvolvimento Econômico e Social (BNDES) revelou, no seu relatório final, o seguinte dado: "O PIB brasileiro apresentou um crescimento de 16\% entre 1995 e 2003, enquanto no mesmo período o faturamento declarado pelas editoras teve uma queda de 48\%" (EARP, 2005, p.29 e 30). Dessa forma, fica claro que a indústria editorial não contribuiu para o aumento do PIB. Altbach (1997), citado por Oddone (1998, p. 30), diz que:

[...] A atividade editorial tem uma importância que ultrapassa seu limitado papel econômico, porque ela é essencial à vida cultural, científica e educação das nações. [...] A produção de livros - que reflete de maneira direta a cultura, a história e os interesses de uma nação ou de um povo - é algo que não pode ser transferido a terceiros. [...] Essa é uma parte vital de uma cultura. Nesse sentido, a atividade editorial é diferente, merecendo consideração especial. [...].

Transformar o Brasil em um país de leitores não é tarefa fácil, sobretudo no contexto da sociedade da informação, no qual novos suportes informacionais direcionam as políticas não apenas para as práticas leitoras e para a alfabetização cidadã, mas principalmente para o domínio das novas tecnologias, muitas vezes distantes da formação do cidadão leitor e apenas instrumentalizadoras de habilidades primárias que têm como objetivo incluir o cidadão nessa sociedade. Para Barros (2005, p. 3),

desde que a indústria editorial se implantou no Brasil, no início do século XIX, sempre houve políticas públicas voltadas para o livro, o que tem variado é o caráter [...] que transitaram entre o controle, a repressão, a distribuição gratuita, o incentivo à leitura [...].

A falta de continuidade dessas políticas e o pouco envolvimento da sociedade civil e demais atores sociais contribuíram para que o país chegasse ao século XXI com uma média de leitura por ano equivalente a 1,8 livro por habitante, segundo dados da CBL.

\section{POLÍTICAS PÚBLICAS NO BRASIL}

Uma política pública reflete a vontade de diferentes setores da sociedade em avançar para uma determinada direção e representa uma articulação coerente de medidas para transformar uma situação. Sua eficácia se mede por sua sustentabilidade e sua coerência interna, que faz com que nos distintos setores envolvidos tenha repercussão positiva. Uma política pública permite garantir que os problemas não serão crônicos e idênticos aos que sempre existiram (GOLDIN, 2003, p.163). 
Nessa perspectiva de política pública, o Brasil ainda está distante, notadamente, na área cultural e educacional. Historicamente, a política cultural adotada pelo país a partir do século XIX foi protecionista, uma vez que exercia o mecenato junto aos artistas que viviam na Corte e promovia viagens à Europa para jovens talentosos que tinham seus projetos financiados pelo governo, além de postos diplomáticos e políticos para poetas e romancistas em uma verdadeira troca de favores (LINDOSO, 2004, p. 24). Essa situação perdurou durante todo o Império e somente foi alterada no período denominado República Velha, graças à expansão do sistema educacional e à autonomia alcançada em algumas áreas da produção artística.

Na década de 1930, quando o cenário no Brasil era de mudanças econômicas, políticas e culturais, a partir de dois acontecimentos importantes - a Revolução de 30 e o Estado Novo -, foi institucionalizado o primeiro órgão para efetivar "[...] políticas de bibliotecas públicas, mecanismos institucionais que facultavam o compartilhamento, a difusão e o uso da informação disponível para as comunidades" (OLIVEIRA, 1994, p.17). Em pleno governo ditatorial de Getúlio Vargas, por meio do Decreto-lei no 93, de 21 de dezembro de 1937, criou-se o Instituto Nacional do Livro (INL), por iniciativa do ministro da Educação, Gustavo Capanema, com as seguintes competências: organizar e publicar a Enciclopédia Brasileira e o Dicionário da Língua Nacional, editar obras de interesse para a cultura nacional, criar bibliotecas públicas e estimular o mercado editorial mediante promoção de medidas para aumentar, melhorar e baratear a edição de livros no país (OLIVEIRA, 1994, p.43). A origem do INL resultou da incorporação das funções do Instituto Cairu, criado no mesmo ano para produzir a Enciclopédia Brasileira, e o Plano Nacional de Educação (PNE). Conforme explica Silva, o Plano foi um documento

[...] que consolidava os intensos debates, que ocorreram nos anos 20 e 30, sobre o sistema educacional brasileiro. Debates objetivando ampliar o acesso da população à educação, definir as responsabilidades da União, estados e municípios em assuntos educacionais, propor currículos e métodos de ensino, enfim, dotar o país de uma política nacional de educação, até então inexistente (SILVA, 1992, p.20).

Em 1973, o Instituto é reestruturado por meio do Decreto no 72.614, de 15 de agosto, e nas suas atribuições passa de "editor" para "promotor de publicações" não apenas de interesse a cultura nacional, mas também de interesse educacional, científico e cultural (OITICICA, 1997, p. 6). Esse foi o período em que o INL mais beneficiou a iniciativa privada, transferindo a sua linha editorial para editoras comerciais estabelecidas.

A avaliação da atuação do INL nos seus 52 anos de existência, de 1937 a 1989, é um tanto quanto polêmica. No que diz respeito ao mercado livreiro do país, o instituto buscou

[...] contribuir para a criação de uma cultura nacional [...] centrou seu trabalho no livro, como instrumento de estabilidade social e transmissão desta cultura (OLIVEIRA, 1994, p. 43).

No entanto, na análise de Miceli,

estas competências do instituto, agregadas às políticas de cooptação de intelectuais para o trabalho em organismos governamentais e de censura da atividade intelectual, permitiram ao Estado Novo controlar todo o ciclo de produção cultural impressa, desde a elaboração, passando pela editoração e comercialização, até sua divulgação (MICELI, 1979, p.159).

Para Oiticica, a transferência da linha editorial do INL para o setor privado não privilegiou a difusão do livro nem o estímulo à leitura, questão que se manteve insolúvel,

[...] o alvo imediato [...] não era necessariamente o público, mas a iniciativa privada, que além da exclusividade do mercado e da subvenção de seus custos, ganhava ainda o redimensionamento das compras de parte da edição pelo Estado [...] (OTICICA, 1997, p.7).

Ficou patente que a simples oferta de livros não garantiu a formação de práticas de leitura. Esta é uma crítica que se faz às ações do instituto, que deixou de lado mecanismos de desenvolvimento e formação leitora que

[...] deveriam ser ativados nas comunidades, concentrando sua ação na mera distribuição de obras como instrumento de enraizamento da biblioteca na sociedade (OLIVEIRA, 1994, p.71).

A intervenção do Estado, pelo INL, na qualidade da difusão da informação pelos livros que comporiam os acervos das bibliotecas públicas foi bastante clara, sobretudo no período pós-64 
[...] sob o regime de co-edição a partir da Portaria no 35, de 11/3/70, o INL censurou diversas propostas de publicação através de pareceres que introjetavam a repressão do período (OITICICA, 1997, p. 2).

Ao mesmo tempo, o INL não conseguiu implementar a criação da Enciclopédia Brasileira e o Dicionário da Língua Nacional, que constava do decreto de sua criação.

Considerando o quadro político, econômico e cultural daquele período, as ações do INL não devem ser tomadas apenas nos seus pontos negativos. Sua contribuição para o desenvolvimento da biblioteca pública no Brasil foi expressiva, bem como no desenvolvimento da biblioteconomia para a formação de recursos humanos especializados. Em 5 de novembro de 1987, por meio da Lei no 7.624, o Instituto Nacional do Livro e a Biblioteca Nacional passaram a integrar a Fundação Nacional PróLeitura, que em 12 de abril de 1990 foi extinta, pela Lei no 8.029, sendo suas atribuições transferidas para a Fundação Biblioteca Nacional.

\section{SITUAÇÃO ATUAL DAS POLÍTICAS PÚBLICAS}

A partir da década de 80 , após o período ditatorial, algumas políticas foram empreendidas para a área cultural, com as chamadas leis de incentivo, como foi a Lei n⿳⺈ 7.505 de 20 de junho de 1986 - Lei Sarney criada pelo presidente José Sarney e substituída em 1991 pela Lei no 8313 - Lei Rouanet - elaborada pelo diplomata, ensaísta e cientista político Sérgio Paulo Rouanet, secretário de Cultura da Presidência (1991/ 1992) no Governo Fernando Collor.

A Lei Rouanet engloba todo o setor cultural e instituiu o Programa Nacional de Apoio à Cultura (Pronac), com a finalidade de captar e canalizar recursos para a cultura, e a Comissão Nacional de Incentivo a Cultura (CNIC), responsável pela análise dos projetos que se candidatam a receber incentivos da Lei. Ficou estabelecido que o Pronac captará recursos por meio do Fundo Nacional de Cultura (FNC), anteriormente denominado Fundo de Promoção Cultura, Fundo de Investimento Cultural e Artístico (Ficart) e outros incentivos a projetos culturais. Tais incentivos poderão ser concedidos por pessoa jurídica ou pessoa física, as quais utilizarão descontos do imposto de renda até o limite de $4 \%$ do valor devido para empresa e de 6\% para pessoa física. Quanto aos recursos do FNC, serão captados das empresas e outros setores previstos na lei, dentre os quais $1 \%$ da arrecadação dos fundos de investimentos regionais e $3 \%$ oriundos das loterias federais.
Nas suas disposições preliminares, a Lei Rouanet avança em relação às práticas intervencionistas do Estado na produção cultural e prevê a promoção da regionalização da produção cultural, o livre acesso às fontes de cultura, a valorização das manifestações culturais e de seus criadores, a preservação dos bens materiais e imateriais do patrimônio cultural e histórico brasileiro; o estímulo à produção e difusão de bens culturais de valor universal formadores e informadores de conhecimento, cultura e memória e prioridade ao produto cultural nacional. Bastante abrangente nas suas disposições, cita especificamente projetos na área editorial no Capítulo III, quando se refere ao uso do Fundo de Investimento Cultural e Artístico. No item III, trata da "edição comercial de obras relativas às ciências, às letras e às artes, bem como de obras de referência e outras de cunho cultural" e, no Capítulo IV, sobre incentivo a projetos culturais, cita, no parágrafo terceiro, os segmentos a serem beneficiados: no item b, consta "livros de valor artístico, literário ou humanístico" (BRASIL, 1991).

Embora bastante abrangente nas suas ações, a Lei Rouanet recebe várias críticas quanto à sua eficácia e à concentração das ações nas regiões Sudeste e Sul, onde estão situadas as grandes empresas que têm, de fato, interesse em financiar projetos culturais. $\mathrm{Na}$ área editorial, quase que exclusivamente livros de arte são contemplados e, mais recentemente, projetos de livros em Braille. Segundo Dória (2003, p. 1),

[...] não há muita transparência nos dados que permitiriam julgar a eficácia da Lei Rouanet, mas também falta às análises uma clara consciência do sentido democrático que deveria perseguir uma lei que destina recursos do tesouro para atividades públicas. Ora, num país onde as leis costumam "pegar" ou "não pegar", a Lei Rouanet inaugura uma nova modalidade: a das leis que "pegam" e fracassam. Ela não fracassou por falta de adesão, mas por excesso de adesão interesseira, contemplando apenas a perspectiva dos ganhos econômico-financeiros que promete.

Ao completar 15 anos, em 2006, a Lei Rouanet continua provocando polêmica, mesmo após um ano e meio de discussões organizadas pelo Ministério da Cultura em todo o país, que resultaram em um novo decreto que regulamenta a Lei Federal de Incentivo à Cultura. As mudanças, para alguns, tímidas, para outros prejudiciais aos denominados captadores de recursos, não alteram os percentuais de renúncia fiscal, o que deverá acontecer no texto reformulado da lei que brevemente 
tramitará no Congresso Nacional. Na opinião de Paulo Oliver, conselheiro da área de humanidades da CNIC do Ministério da Cultura e vice-presidente do Instituto Interamericano de Direito Autoral,

[...] a noiva é a mesma, só mudou o vestido [...] o que deveria mudar é a ótica de análise dos processos. Há projetos bons, mas às vezes não são bem fundamentados (O INCENTIVO, 2006).

Outras políticas para o setor surgiram expressas na forma de leis mais específicas, como é o caso da Lei do Direito Autoral - Lei 9.610/98 - e a denominada Política Nacional do Livro - Lei 10.753/2003 -, sendo esta voltada para as questões do livro; por meio dela instituiu-se "[...] o instrumento legal que autoriza o Poder Executivo criar e executar projetos de acesso ao livro e incentivo à leitura" (BRASIL, 2005). As políticas também se manifestaram por meio de programas governamentais, como Próleitura, Programa Nacional de Incentivo à Leitura (Proler), Fome do Livro e Vivaleitura, assim como programas mais específicos voltados para o livro didático e a biblioteca escolar - Programa Nacional de Biblioteca Escolar (PNBE) e o Programa Nacional de Livro Didático (PNLD).

Uma atualização da Lei do Direito Autoral ocorreu em 19 de fevereiro de 1998, e entrou em vigor a Lei 9.610/ 98, a qual ampliou os suportes possíveis para difusão da informação, englobando as novas tecnologias. Baseia-se em convenções internacionais assinadas pelo Brasil. No capítulo I, Título IV, trata especificamente da edição, e é enfática na relação autor / editor, no que se refere à reprodução, conforme tratado no capítulo 2 .

Em 30 de outubro de 2003, foi sancionada a Lei no 10.753, a "Lei do Livro" proposta pelo senador José Sarney e que instituiu a Política Nacional do Livro. Esta lei trata de questões pontuais relacionadas ao livro, desde a política nacional para a difusão e a leitura, até a editoração, distribuição e comercialização. A sua regulamentação

\section{[...] deverá apresentar o Plano Nacional do Livro e}

Leitura, de caráter trienal, e formas possíveis para a organização e estruturas capazes de formular, coordenar e executar ações dessa política setorial (CSLL).

O Artigo $7^{\text {o }}$ do capítulo III dessa lei prevê o estabelecimento de linhas de crédito específicas para o financiamento das editoras e distribuidoras de livro. Essas linhas de crédito tornaram-se disponíveis, em 2005, por meio do Banco Nacional de Desenvolvimento Econômico e Social (BNDES), que, após estudo encomendado ao Grupo de Pesquisa em Economia do Entretenimento do Instituto de Economia da Universidade Federal do Rio de Janeiro, intitulado "O desenvolvimento da cadeia produtiva do livro no Brasil em perspectiva internacional comparada: propostas de ações públicas e privadas na construção de uma agenda de transformação setorial”, estabeleceu parâmetros e normas para a liberação de crédito para o setor produtivo do livro.

A Lei do Livro não é algo novo. Entre 1974 e 1976, um grupo de editores e livreiros representando a CBL e o SNEL preparou um anteprojeto da lei, que, quando concluído, foi encaminhado ao ministro da Educação, Ney Braga, durante o governo do presidente Geisel, que não deu a devida importância ao documento (HALLEWELL, 2005, p. 597).

O Plano Nacional do Livro e da Leitura (PNLL) foi apresentado pelos ministros da Cultura e da Educação, no dia 13 de maio de 2006, no encerramento do FÓRUM - PNLL/Vivaleitura 2006/2008. No documento apresentado, é dito que o PNLL

[...] é uma ação liderada pelo governo federal para converter esse tema em política pública mediante a concentração e articulação dos esforços desenvolvidos pelos diversos atores sociais: Estado, universidade, setor privado e demais organizações da sociedade civil que formam o chamado terceiro setor. Tem como objetivo central melhorar a realidade da leitura no país e, por isso, é construído e se desenvolve por meio de um processo que transcende a imediatez (PNLL, 2006, p.5).

O PNLL possui quatro eixos estratégicos, vinte linhas de ação e um calendário anual de eventos. Os quatro eixos são os seguintes: democratização do acesso; fomento à leitura e à formação; valorização da leitura e da comunicação; apoio à economia do livro. No primeiro eixo - democratização do acesso -, contém uma referência à "melhoria do acesso ao livro e a outras formas de cultura letrada" e "incorporação e uso de novas tecnologias" (2006 p.6). Essa ressalva é importante, uma vez que, no Capítulo II - DO LIVRO, na Lei no 10.753 , o livro não foi pensado e definido dentro dos parâmetros da sociedade da informação e dos novos suportes possíveis, salvo no item VII, que trata de livros em meio digital para "uso exclusivo de deficientes visuais” (BRASIL, 2003). 
Um longo caminho foi percorrido até se chegar ao PNLL. No início do atual governo, a Secretaria do Livro e da Leitura (SNLL) foi extinta, e suas atribuições passaram à Fundação Biblioteca Nacional (FBN). Antes de ser extinta, a SNLL, responsável pela política do livro e da leitura no país, teve como secretário o poeta baiano Wally Salmão. Com a morte de Salomão em maio de 2003, a secretaria foi extinta, obedecendo a projeto do próprio secretário. Em 2004, é criado o Programa Fome do Livro, denominação bastante emblemática do populismo do governo, ligado à FBN, que resultou de

[...] parte dos esforços do governo federal na tarefa de se construir uma política pública nacional para o livro, a leitura e a biblioteca pública no Brasil (BIBLIOTECA NACIONAL, 2005).

Assumiu sua coordenação Galeno Amorim, ex-secretário de cultura de Ribeirão Preto, primeiro município brasileiro a implantar uma lei do livro, Lei no 9.353, de 5 de outubro de 2001.

Em julho de 2004, realizou-se em Ribeirão Preto o I Encontro Preparatório para o Fórum Nacional da Leitura, coordenado por Galeno Amorim, cujo objetivo era apresentar o Programa Fome do Livro e discuti-lo com os vários segmentos ligados ao livro e à leitura. Esse programa foi debatido em centenas de cidades brasileiras no decorrer do ano. A receptividade do programa aparentemente não convenceu o então presidente da FBN, Pedro Côrrea do Lago, e o ministro da Cultura, Gilberto Gil, tomou a seguinte medida "[...] tirou a coordenação do Programa Fome do Livro/ Plano Nacional do Livro e da Leitura de sob as asas da Fundação Biblioteca Nacional" (WASSERMAN, 2005).

De fato, a missão da FBN é ser

depositária do patrimônio bibliográfico e documental do Brasil, [...] tem o objetivo de garantir a todos os cidadãos, desta e das futuras gerações, o acesso a toda memória cultural que integra seu acervo (BIBLIOTECA NACIONAL, 2005).

Cabe à Fundação cuidar do acervo, preservá-lo, recuperálo e disponibilizá-lo; políticas de leitura cabem a outras instâncias. Em 2002, a Câmara Brasileira do Livro entregou um documento aos candidatos à Presidência da República, no qual alertava sobre a missão da Biblioteca Nacional, a qual deveria ser

[...] focar o importante trabalho de preservação de seu valioso acervo e deixar a política do livro e da leitura para um órgão independente, capaz de dialogar com várias instâncias do governo para que o assunto deixasse de ser tratado como "perfumaria cultural" (WASSERMANN, 2005).

O ano de 2004 se encerrou de forma bastante otimista para os que fazem parte da denominada cadeia produtiva do livro. Em 21 de dezembro, o presidente Luiz Inácio Lula da Silva sancionou a lei de desoneração fiscal, que isenta "[...] a produção, comercialização e importação de livros do pagamento do PIS/Cofins/Pasep, o que varia entre 3,655 a 9,25\%" (SCORTECCI; PERFETTI. 2006, p. 29) Desse modo, editores, livreiros e distribuidores não mais pagarão qualquer tipo de taxa ou imposto sobre operações com livro, gozando, pois, de imunidade tributária, conforme prevê a Constituição, na Seção II Das Limitações do Poder de Tributar, Art. 150, inciso VI, alínea d (BRASIL, 2005). A desoneração é vista por alguns de forma bastante otimista, sobretudo pelo próprio governo, como garantia de uma redução no preço do livro, fato que não está assegurado. $\bigcirc$ Ministério da Cultura prevê

[...] que a lei vai causar dois tipos de impactos imediatos no mercado editorial brasileiro. Um deles é a redução dos preços nos livros, prevista para ocorrer já a partir deste mês e que deve chegar a 10\% em três anos. A outra conseqüência é a retomada dos investimentos por parte de editores e livrarias para lançamentos de novos selos editoriais e a abertura de pontos de venda ainda no primeiro semestre deste ano (SCORTECCI; PERFETTI; 2006, p. 29).

A contrapartida dos empresários do livro à desoneração fiscal é oferecer "espontaneamente" $1 \%$ sobre o resultado da venda de livros para criar o Fundo Pró-Leitura. A expectativa do Fundo é gerar recursos da ordem de $\mathrm{R} \$ 45$ milhões anuais a serem utilizados em projetos e programas para fomentar a leitura, as bibliotecas e conseqüentemente a própria indústria editorial. Em outubro de 2005, cinco entidades do livro - Associação Brasileira de Difusão do Livro (ABDL), Associação Brasileira de Editores e Livreiros (Abrelivros), Associação Nacional de Livrarias (ANL), Sindicato Nacional de Editores de Livros (SNEL) e Câmara Brasileira do Livro $(\mathrm{CBL})$ - assinaram a ata de criação do Fundo. Os primeiros recursos do Fundo foram utilizados em uma campanha de incentivo à leitura, com a participação em caráter voluntário dos atores "globais" Reynaldo Gianecchini e Cleo Pires. O objetivo da campanha era mostrar o livro como fonte de lazer e entretenimento; no entanto a sofisticação do cenário dos clips continua reforçando a 
idéia do livro como um lazer de elite. A escolha de atores que não têm uma trajetória profissional consolidada e popularizada junto às camadas sociais que seriam o foco da campanha, assim como os livros apresentados como leituras desses atores desconhecidos do grande público, faz com que os clips não fixem a imagem de popularizar a leitura.

$\mathrm{Na}$ mesma solenidade de assinatura da Lei de Desoneração, foi lançado o calendário do Ano IberoAmericano do Livro e da Leitura (Ilimita), que no Brasil recebeu a denominação de Vivaleitura. Coordenado pela Organização dos Estados Ibero-Americanos (OEI), Centro Regional para o Fomento do Livro na América Latina e Caribe (Cerlalc), Unesco e governos dos países da região, esse programa teve como objetivo gerar políticas que contribuíssem para uma mudança de cenário para o livro e a leitura nos países iberoamericanos, em uma tentativa de reverter os baixos índices de leitura dos seus cidadãos. O Ilimita foi deliberado na XIII Reunião Anual de Cúpula IberoAmericana dos Chefes de Estado e de Governo, realizada em novembro de 2003, em Santa Cruz de La Sierra, na Bolívia (CERLALC, 2004).

No Brasil, o Ano Ibero-Americano do Livro e da Leitura/ Vivaleitura realizou inúmeras ações, tais como identificar e apoiar projetos já existentes, criar medidas para promoção do livro e da leitura, articular com todos os segmentos da sociedade - instituições de ensino, iniciativa privada, representantes do mercado editorial, instituições não-governamentais. Essas ações incentivaram a criação da Câmara Setorial do Livro e Leitura (BRASIL, 2005), que faz parte dos órgãos consultivos do Sistema Minc e será acolhida pelo Conselho Nacional de Política Cultural (CNPC).

A Câmara Setorial do Livro e Leitura é composta por 26 membros, desde representante dos Ministérios da Cultura e da Educação, como das diversas entidades do segmento livreiro, dos escritores, dos bibliotecários, além de representantes das cinco regiões do país. A instalação e a posse do CSLL ocorreram em dezembro de 2005, e na oportunidade foi discutida e elaborada a proposta do PNLL, lançada em março de 2006. No momento, esse plano passa por uma consulta pública disponível no site www.pnll.gov.br.

O Plano, que esteve a cargo de Galeno Amorim até abril de 2006, está sob a coordenação de José Castilho Marques Neto e contará com um comitê executivo a ser instituído pelos ministérios da Cultura e da Educação. Segundo
Castilho, a Coordenação Geral do PNLL poderá ser instalada tanto no Ministério da Cultura quanto na Biblioteca Nacional, porém o Comitê Executivo será o interlocutor do PNLL e dos participantes do universo editorial, para que haja maior dinâmica (PNLL, 2006).

\section{PROGRAMAS GOVERNAMENTAIS PARA O LIVRO DIDÁTICO E PARA LEITURA}

Sob a tutela do governo federal, por intermédio do MEC, existem ainda os programas específicos voltados para aquisição do livro didático para as escolas públicas Programa Nacional de Livro Didático (PNLD), Programa Nacional de Livro Didático para o Ensino Médio (PNLEM) - e para as bibliotecas escolares - Programa Nacional de Biblioteca Escolar (PNBE). Essas aquisições, pelo volume de recursos que envolvem, sempre geraram uma disputa entre as editoras de livros didáticos e paradidáticos nacionais e, nos últimos anos, a cobiça das editoras estrangeiras que se instalaram no Brasil.

Os programas governamentais de distribuição de livros didáticos se iniciaram em 1938, com o Decreto-Lei no 1006, que, sob a coordenação do MEC, instituiu a Comissão Nacional do Livro Didático (CNLD). A finalidade dessa comissão era estabelecer condições para produção, importação e utilização do livro didático. Em 1966, foi criada a Comissão do Livro Técnico e do Livro Didático (Colted), com o objetivo de coordenar as ações referentes à produção, edição e distribuição do livro didático. Em 1971, essa atribuição passou para o INL, por meio do Programa do Livro Didático para o Ensino Fundamental (Plidef) (BRASIL, 2004).

Em 1976, a Fundação Nacional do Material Escolar (Fename) foi criada e assumiu, além das atribuições referentes ao material escolar, a execução do programa do livro didático. Até a implantação do PNLD e do PNLEM, várias outras denominações e siglas foram substituindo os programas existentes. Em 1983, a Fundação de Assistência ao Estudante (FAE) assumiu as atribuições da Fename. No ano de 1985, com a edição do Decreto no 91.542, de 19/8/85, o Plidef foi substituído pelo Programa Nacional do Livro Didático (PNLD) e ocorreram algumas mudanças: indicação dos livros pelos professores, extinção do livro descartável para permitir a sua reutilização, aperfeiçoamento das especificações técnicas para produção dos livros, ampliação da oferta para os alunos de todas as séries e, finalmente, a participação dos professores no processo de escolha dos livros e o fim da participação financeira dos estados. 
Atualmente, o Fundo Nacional de Desenvolvimento da Educação/FNDE mantém, com recursos financeiros do Orçamento Geral da União e da arrecadação do salárioeducação, os programas voltados para o livro didático PNLD e PNLEM. Adotou-se um processo de análise para a aquisição dos livros a serem distribuídos e, a cada três anos, é lançado um edital com os critérios estabelecidos a fim de que os detentores dos direitos autorais inscrevam as obras didáticas. $O$ processo de avaliação conta com a participação das universidades, uma vez que envolve livros de todas as disciplinas do currículo da educação básica. Ao final do processo de avaliação, é elaborado o Guia dos Livros Didáticos contendo resumo das obras para que os professores das escolas procedam à escolha dos livros a serem adotados. A principal crítica que se faz a esses programas voltados para o livro didático é a seguinte:

A acentuada centralização da participação de um grupo de editores no PNLD coloca em questão as perspectivas de descentralização do programa. $\mathrm{Na}$ medida em que, por sua posição no mercado, dispõe de mecanismos mais eficientes de divulgação, de marketing [...] alcançam grande poder de penetração e circulação entre seus "clientes". Essa situação, associada a outros fatores, condiciona, em grande medida, a escolha feita pelo professor (HÖFLING, 2000, p.9)

O PNBE foi criado em 1997, por meio da Portaria Ministerial no 584, de 28 de abril, e tem como objetivo possibilitar o acesso dos alunos e professores à informação, contribuindo para fomentar a prática da leitura e formação dos professores das escolas de ensino fundamental. Por intermédio desse programa, foram constituídos os acervos das bibliotecas escolares formados por obras de referência, literatura e de apoio à formação dos professores. Esse acervo passa por um processo de escolha e seleção, mediante edital previamente divulgado (BRASIL, 2005).

Quanto aos programas voltados às práticas leitoras, o Pró-Leitura foi criado em 1992 por iniciativa da Secretaria de Educação Básica - MEC em parceria com as secretarias de Educação dos estados, universidades e Embaixada da França. Ele objetivou a formação continuada, oportunizando ao professor a discussão teórica e ampliação do repertório de vivências de leitura e escrita, além de constituir estratégias de reflexão e de intervenção nas práticas pedagógicas. No atual site do MEC, esse programa não está mais acessível. Na página da Secretaria de Educação Básica, faz-se referência à
Política de Formação de Professores e Alunos Leitores, cujo objetivo é similar ao Pró-Leitura.

Voltado para formação de leitores nos espaços sociais, o Proler surgiu em 1992, quando foi institucionalizado por meio do Decreto no 519 de 13 de maio, sob a coordenação do teatrólogo Francisco Gregório e a professora Eliana Yunes. Segundo os coordenadores, o Proler

[...] já tinha como pressuposto o não-estabelecimento de planos verticalizados e acabados para implantação. Pelo contrário, teorias e práticas vêm constantemente sendo repensadas e hoje o Programa continua adequando-se em resposta aos indicadores sinalizados pela sociedade (UNIVERSIDADE FEDERAL DO ESPÍRITO SANTO, 2003).

Atualmente ele está vinculado à Fundação Biblioteca Nacional e tem como sede a Casa da Leitura, no Rio de Janeiro, que dispõe, dentre outras coisas, de centro de referência e documentação para jovens e duas bibliotecas: infantil e juvenil. Sua atuação está vinculada a uma política de leitura e busca colaborar para qualificar as relações sociais, mediante a formação de leitores conscientes e críticos dentro do seu contexto social. Em meados de 1996, a nova direção da Fundação Biblioteca Nacional, por meio da Comissão Nacional, promoveu a integração do Proler com o MEC e outras instituições com experiência de leitura, tais como Fundação Nacional do Livro Infantil e Juvenil (FNLIJ), Associação de Leitura do Brasil (ALB), Programa de Alfabetização e Leitura (Proale/UFF) e Ministério da Educação (MEC).

\section{AVANÇOS}

As discussões em favor de políticas nacionais de leitura, como foi visto, acontecem há alguns anos. Em 1992, por exemplo, foi realizada no Rio de Janeiro, promovida pelo Cerlalc e a Fundação Biblioteca Nacional, a Reunião Internacional de Políticas Nacionais de Leitura para América Latina e Caribe. Nessa reunião, a leitura foi defendida como responsabilidade de todos e recomendava-se que os países participantes criassem programas de efeitos multiplicadores cujo objetivo era atingir maior número de cidadãos - crianças, jovens e adultos - na tentativa de criar condições favoráveis ao desenvolvimento da capacidade leitora. Sobre o Estado e as políticas de leitura, foi dito que

É função primordial do Estado ocupar-se dos direitos básicos da população e de seu desenvolvimento econômico e social. A leitura constitui-se num desses 
direitos e contribui para o desenvolvimento. $O$ que se pede ao Estado é a vontade política para articular, estimular e apoiar experiências qualificadas (REUNIÕES, 1994, p.16) (grifo nosso).

Na publicação que reúne os documentos das Reuniões Internacionais de Políticas Nacionais de Leitura para América Latina e Caribe, ocorridas entre 1992 e 1994, verifica-se que muitas questões colocadas hoje não diferem de 14 anos atrás. Faltou e falta vontade política para avançar. Conforme divulgação do Instituto Paulo Montenegro, o Brasil situa-se "[...] em último lugar numa avaliação que mediu a capacidade de leitura em 32 países" (A MELHOR, 2006).

A política pública do governo para o livro, leitura e biblioteca que, desde 2003, a partir da Lei do Livro, tem sido discutida e avaliada por todo o segmento da denominada cadeia produtiva do livro e com a sociedade em geral, precisa ser mais objetiva, a fim de se chegar a ações concretas que de fato revertam os quadros atuais. Observa-se que, dentre as políticas propostas, o ensino superior não é contemplado. Sabe-se que a realidade do estudante universitário é de baixa freqüência nas bibliotecas e de leituras fragmentadas por meio de cópias de livros. Embora vivendo na sociedade da informação, o acesso a esta informação está abaixo do desejável. A tecnologia faz parte do dia-a-dia de muitos estudantes, mas está longe de ser utilizada para ampliar o conhecimento mediante o acesso a portais confiáveis.

Artigo submetido em 27/10/2005 e aceito em 24/04/2007.

\section{REFERÊNCIAS}

A MELHOR escola para alfabetizar. Veja, São Paulo, n. 16, p. 118, abr. 2006.

AMERICAN LIBRARY ASSOCIATION - ALA. Report of the presidential commitee on information literacy: final report. [S.1.], 1989. Disponível em: <http://www.ala.org/ala/acrl/acrlpubs/whitepapers/ presidential.htm >. Acesso em: 06 ago. 2005.

AFP. Brasil tem índice de desenvolvimento médio (ONU). 2005. Disponível em: <http://ultimosegundo.ig.com.br/materias/economia/21050012105500/2105414/2105414_1.xml>. Acesso em: 01 abr. 2006.

BARROS, Susane S.; JAMBEIRO, Othon; BORGES, Jussara. Políticas públicas para o livro e a leitura e sua influência na indústria editorial de Salvador. In: CONGRESSO BRASILEIRO DE CIÊNCIAS DA COMUNICAÇÃO, 28., 2005, Rio de Janeiro. Anais... Rio de Janeiro:UERJ, 2005.

BIBLIOTECA NACIONAL (Brasil). Projetos especiais: Programa Fome de Livro. Disponível em: < http://www.bn.br/script/ FbnFomePrincipal.asp >. Acesso em: 15 jan. 2005.
BRASIL. Constituição (1988). Constituição da República Federativa do Brasil. 25. ed. Brasília: Câmara dos Deputados, Coordenação de Publicações, 2005. (Série textos básicos, n. 37).

Lei 8.313, de 23 de dezembro de 1991. Restabelece princípios da lei no 7.505, de 2 de julho de 1986, institui o Programa Nacional de Cultura - PRONAC. Brasília, DF, 23 dez. 1991. Disponível em: <http://www.minc.gov.br/legisl/docs/L-008313.htm>. Acesso em: 14 abr. 2006.

. Lei 10.753 , de 30 de outubro de 2003. Institui a política nacional do livro. Disponível em: < https://www.planalto.gov.br/ ccivil_03/LEIS/2003/L10.753.htm >. Acesso em: 25 abr. 2004.

- Ministério da Cultura. Instalação da câmara setorial do livro e da leitura. São Paulo, 2005. 74 p.

. Ministério da Educação. Secretaria de Educação Básica. Coordenação Geral de Estudos e Avaliação de Materiais. Disponível em: $<$ http://www.mec.gov.br/sef/fundamental/avaliv.shtm >. Acesso em: 27 out. 2005.

. Fundação Nacional do Desenvolvimento da Educação. Livro Didático. 2004. Disponível em:

$<$ http://www.fnde.gov.br/home/index.jsp?arquivo=/livro_didatico/ livro_didatico.html\#historico >. Acesso em: 23 maio 2004 .

CERLALC. Agenda de políticas públicas de leitura: plano iberoamericano de lectura. Colômbia: ILÍMITA, 2004.

CHARTIER, Roger. As aventuras do livro: do leitor ao navegador. São Paulo: UNESP, 1998.

CROPANI, Ottaviano de Fiori. Livro, biblioteca e leitura no Brasil. Brasília: [s.n.], 1998. Disponível em: <http://www9.cultura.gov.br/ textos/of01.htm>. Acesso em: 26 jun. 2004.

DORIA, Carlos Alberto. É chato dizer, mas a Lei Rouanet fracassou. Revista Trópico, São Paulo, 2003. Disponível em: <http:// pphp.uol.com.br/tropico/html/textos/1411,1.shl>. Acesso em: 14 abr. 2006.

ECO, Humberto. Muito além da Internet. São Paulo: [s.n.], 2003. Disponível em: <www2.fgv.br/biblioteca/geral/docs/Internet.pdf >. Acesso em: 16 dez. 2004.

EARP, Fábio Sá; KORNIS, George. A economia da cadeia produtiva do livro. Rio de Janeiro: BNDES, 2005.

FREITAS, Lídia S.; SILVA, Maurício da. Leitura e universidade: reflexões para a construção de uma outra história. In: ALGUMAS reflexões sobre o ensino e práticas na área de informação. Niterói: EDUFF, 1998. p. 83-95. (Estudos e Pesquisas, 2).

GOLDIN, Daniel. En torno a las políticas públicas del libro y la lectura. In: PASAJES de la edición: hablan los profesionales. Guadalajara: Cerlalc: Universidad de Guadalajara, 2003. p. 162-168.

HALLEWELL, Laurence. O livro no Brasil. 2. ed. São Paulo: Editora da Universidade de São Paulo, 2005.

HÖFLING, Eloísa de Mattos. Notas para discussão quanto à implantação de programas de governo: em foco o Programa Nacional do Livro Didático. Educação Social, Campinas, v. 21, n. 70, abr. 2000. Disponível em: <http//www.scielo.br/scielo.php?pid=Soioi$73302000000100009 \&$ script $=$ sci_arttext $>$. Acesso em: 03 abr. 2004.

LINDOSO, Felipe. O Brasil pode ser um país de leitores?: política para cultura/ política para o livro. São Paulo: Summus Editorial, 2004. 
LIVRO pra que te quero. A Tarde, Salvador, p. 3, 06 mar. 2005.

MARINHO, Marildes. Pró-leitura, perspectivas interdisciplinares: a formação do professor. In: ENCONTRO DE EXTENSÃO DA UFMG, 7., 2004, Belo Horizonte. Anais eletrônicos... Belo Horizonte: UFMG, 2004. Disponível em : <http://www.ufmg.br/proex/arquivos/7Encontro/ Indice2.htm >. Acesso em: 13 abr. 2006.

MICELI, Sérgio. Intelectuais e classe dirigente no Brasil (1920-1945). São Paulo: Difel, 1979.

ODDONE, Nanci Elizabeth. Atividade editorial $\mathcal{E}$ ciência da informação: convergência epistemológica. 1998. Dissertação (Mestrado em Ciência da Informação)- Faculdade de Estudos Sociais Aplicados, Universidade de Brasília, Brasília, 1998.

OliVEIRA, Zita Catarina Prates. A biblioteca "fora do tempo": políticas governamentais de biblioteca públicas no Brasil, 1937-1989. 1994. 221 f. Tese (Doutorado em Ciência da Comunicação) - Escola de Comunicação e Artes, Universidade de São Paulo, São Paulo, 1994.

O INCENTIVO à cultura. Panorama Editorial, São Paulo, v. 2, n. 19, p. 14-17, maio 2006.

OITICICA, Ricardo. O Instituto Nacional do Livro e as ditaduras: academia brasílica dos rejeitados. 270 f. Tese (Doutorado em Literatura:literaturas de língua portuguesa) - Departamento de Letras, Pontifícia Universidade Católica do Rio de Janeiro, Rio de Janeiro, [s.d.].
PLANO Nacional do Livro e da Leitura - PNLL. 2006.

PNLL em novas mãos. Panorama Editorial, São Paulo, v. 2, n. 19, p. 28 31, maio 2006.

REUNIÕES internacionais de políticas nacionais de leitura: América Latina, Caribe-Mercosul, pacto amazônico e grupo dos três. [S.l.: s.n.], 1994. 56 p.

SCORTECCI, João; PERFETTI, Maria Esther Mendes. Informações importantes para quem quer escrever e publicar um livro: guia do profissional do livro. São Paulo: Scortecci, 2006.

SILVA, Suely Braga da. O Instituto Nacional do Livro e a institucionalização de organismos culturais no Estado Novo (1937-1945): planos, idéias e realizações. 1992. 154 f. Dissertação (Mestrado em Ciência da Informação)- Universidade Federal do Rio de Janeiro, Rio de Janeiro, 1992.

WASSERMANN, Raul. Livros, leitura, desenvolvimento. O livro é um importante fator de desenvolvimento econômico e social de uma nação, uma verdade nem sempre lembrada?. Desafios do desenvolvimento, Brasília, 01 jan. 2005. Disponível em: <http://www.desafios.org.br/ Edicoes/6/artigo13076-1.asp?o=s>. Acesso em: 12 abr. 2006.

UNIVERSIDADE FEDERAL DO ESPÍRITO SANTO. Núcleo de educação aberta e à distância. 2003. Apresenta arquivo de informes sobre eventos promovidos e informações úteis à comunidade. Disponível em: <http://www.neaad.ufes.br/>. Acesso em: 23 abr. 2006. 